\title{
Collaborative Virtual Environments to Support Communication and Community in Internet-Based Distance Education
}

\author{
Sam Redfern and Niall Naughton \\ National University of Ireland, Galway, Ireland
}

\begin{abstract}
sam.redfern@nuigalway.ie niallgnaughton@yahoo.co.uk
\end{abstract}
\begin{abstract}
In this paper we discuss the use of modern information and communication technologies for distance education (DE) purposes. We argue that current technologies and implementations do not adequately support the key concepts of communication and community that many practitioners believe to be important, particularly if modern pedagogies such as constructivism are to be supported. We propose that collaborative virtual environments (CVEs) are appropriate tools for improving DE, and we discuss the current developments in the areas of CVEs in particular and in computer supported co-operative work (CSCW) in general. We also note those areas in which the majority of CVEs implemented to date have not reached their full potential for DE support, discuss current thought regarding online community, and outline a proposed CVE-based system for DE.
\end{abstract}

Keywords: Distance Education, Online Learning Communities, Collaborative Virtual Environments

\section{Introduction}

The majority of pre-packaged multimedia education products are educationally poor - they simply deliver content with no recourse to assisting students to construct their own understanding or problem-solving skills (Chambers 1999). The majority of web-based education resources continue this unfortunate tradition: the approach of one-way course content delivery has prevailed over socially interactive learning approaches. While the Internet is an ideal medium for delivering education "anytime, anywhere", educational institutions must be careful not to simply implement on online version of the traditional "one-way" correspondence model. While media-rich web-based courses are quite economical and easy to implement, we need to focus more on the pedagogical issues of distance learning as opposed to the technological issues of web-based media (Hiltz 1998).

The longstanding literature of Distance Education (DE) has documented extensively the problems associated with its practice. The traditional one-way model of DE course delivery fails primarily because of the lack of support for social interaction. When interaction between student and instructor is constrained, questions can remain unanswered, information can be misinterpreted and never corrected, and instructors fail to gauge reaction to their courses. Another critical issue is the lack of interaction between students

Material published as - fine or in print, is copyrighted by Informing Science. Permission to make digital or paper copy of part or all of these works for personal or classroom use is granted without fee provided that the copies are not made or distributed for profit or commercial advantage AND that copies 1) bear this notice in full and 2) give the full citation on the first page. It is permissible to abstract these works so long as credit is given. To copy in all other cases or to republish or to post on a server or to redistribute to lists requires specific permission from the publisher at Puiblister@intommingscience.or themselves: not being part of a campus population of students limits the provision of a socially supportive framework within which effective learning can take place. Studies have shown that these issues result in the specific problems of high dropout rates, isolation, procrastination, and poor motivation which plague DE (e.g. Bernard et. al. 2000). 
An alternative to the pedagogical one-way model where learning is an individual responsibility is the constructivist approach, which sees learning not as an isolated individual act, but a collective result of social interaction. New knowledge is constructed by "anchoring" accumulated knowledge to the alternative points of view, understanding, and experiences of others. (Strommen \& Lincoln 1992). To implement such a pedagogical model requires the building of a community of socially interdependent scholars; a learning community. While it may be possible for this to happen in a relatively natural and unplanned way in traditional "face-to-face" education, to do so in a DE context requires that software packages explicitly focus on the subtleties of developing strong, supportive, and trustful social relationships.

If computers (and the Internet) are to be used to mediate the process of DE, software designers must pay special attention to the issues of sociability and community development. In order to avoid a "high potential for misunderstanding" in communication, an ability to express non-verbal social cues is needed to: communicate an understanding of material discussed; signal a participant's turn to speak; and, obtain a better understanding of the material communicated by observing the speaker's non-verbal cues (Preece 2000). In order to provide an effective collaborative learning community, we must look beyond the capabilities of current text-based Computer Mediated Communication (CMC) tools and address the provision of more highly developed means of mediating the collaborative learning process.

\section{The Need for Communication and Community in Distance Education}

For many years, educators have been exploring ways to combine theories of differing learning styles and student-constructed knowledge with the theory of practice-centred learning. We now consider students to be capable of constructing their own knowledge with guidance from the teacher and in collaboration with fellow students (Berge \& Collins 1995). People do not just learn individually, but through and in interaction with others. The students' ability to create knowledge can thus be enhanced when their instructors use varied instructional delivery formats and learning techniques to provide a richer environment than is used in most DE practiced today. It is clear that modern educational practices require significant collaboration and co-ordination between students. These techniques form the essence of self-directed learning, which is often regarded as being far more appropriate than instructor-directed learning when applied in a DE context (e.g. Jonassen et al. 1995). Palloff and Pratt have called for a "new paradigm" in electronic distance learning, which avoids the typical content-and-facilitator-driven model, and aims to achieve in its place a far more free-flowing and interactive experience, which is more appropriate to the mechanism of delivery (Palloff \& Pratt 1999).

Decades of research on collaborative learning in traditional classrooms support a belief in its general effectiveness (Palloff \& Pratt 1999). Modern CMC technologies offer new opportunities for enhancing the paradigms of DE: collaborative online learning is coming to be regarded as one of the most promising pedagogical approaches for DE (e.g. Eklund \& Eklund 1997). In order for collaborative online learning to take place successfully, it is crucial that the learner feels part of a learning community where his/her contributions add to a common knowledge pool and where a community spirit is fostered through social interactions (Bernard et. al. 2000). In the online classroom it is the relationships and interactions among people through which knowledge is primarily generated: the learning environment needs to be humanised so that personalities "come across the distance" (Baker et. al. 1996).

Informal communications have long been noted as being central to the maintenance of social fabric in the workplace. This, in turn, fosters the sharing of work-related information and the development of collaborations (Whittaker, Frohlich and Daly-Jones, 1994). Studies of the communicational activities in InfoPark, a text-based online community, show that social discussion accounted for more than twice the amount of communication as did work related discussion. The patterns of interaction showed that this social communication provided foundations for the community and that in turn supported the development of effec- 
tive collaborative work-related problem-solving (Evard et. al. 2001). In traditional college education, informal meetings are also crucial to the work activities and social needs of the students. In the time approaching a class, students gather into groups and talk; the same thing typically happens after a class. Much of this activity is of course social rather than explicitly work-oriented; however, it is crucial to the development of a community spirit, which then comes to bear on the collaborative learning that takes place during the course. For teleworkers and telelearners, this sense of community is even more important than in the traditional learning environment (Palloff \& Pratt 1999): it is often considered good practice in both DE and teleworking in general to organise informal face-to-face "getting acquainted" activities in order to strengthen teams and reduce feelings of isolation (Cano et. al. 1999; Bernard et. al. 2000).

\section{Traditional Online Communication Tools Supporting Education}

Before the Internet, the cost of telephone communications and the slowness of study by correspondence often produced a stark contrast between asynchronous modes of distance learning and synchronous experience of a traditional university. Today, online tools have greatly improved distance education. The online communication tools commonly used to support DE provide for both asynchronous and synchronous instruction. Common asynchronous tools include email, listservs, and web bulletin boards. Synchronous tools include chat rooms, application sharing (including whiteboards), tele- and video-conferencing, and occasionally text-based multi-user domains (MUDs/MOOs). Other tools, such as streaming video, webpages, online tests, and computer-based training (CBT) systems are for use by single users, and have little to do with communication and community.

Asynchronous tools have an important role in the "anywhere, anytime" paradigm of distance education that makes it attractive to many people in the first place. Many students report that they feel more at ease with participation when they have time to construct their arguments. Synchronous tools such as whiteboarding, however, are recognized as being very useful for brainstorming-style discussion sessions or small group meetings, which are fundamental to many of the modern educational techniques.

Despite the acknowledged strength of $\mathrm{CMC}$ as a platform for $\mathrm{DE}$, a number of deficiencies in its use as a means of interpersonal communications are discussed in the literature. These deficiencies limit the transmission of interpersonal and social information, including the restriction of "social presence", diminished social-context cues and restricted number of channels, particularly nonverbal modes of expression (Chambers 1999). The crucial requirements for community and richer interpersonal communication are very often badly supported by online tools: we cannot see the facial expressions or body language of colleagues as we conduct discussions; we cannot hear voices or tones of voice to convey emotion. Even as far back as the late 1980s, Nipper discussed the need to create a sense of "synchronous presence" to reduce the social distance between participants; indeed, this need for social connection is a goal that almost supercedes the content-oriented goals for a course (Nipper, 1989).

\section{Enhancing Communication in Online Environments}

The presentation of subtle behaviours such as facial expressions and body language requires communication media that are not bound by limitations of emotional expression. Body gestures and posture can visually illustrate the ideas of a verbal message. Underlying an exchanged message may be an important emotional context that needs to be understood and communicated. As a result, the verbal message must be supplemented with a corresponding visual medium. This dual channel of verbal information and visual body language strengthens the understanding of the communication context.

Most of the non-verbal cues that we take for granted in face-to-face communication simply do not exist in online communications: these include spatial orientation, body posture, hand gesture, glancing, and facial expression. Furthermore, users typically have a very limited awareness of others, who may silently "lurk" 
in text-based environments (Preece 2000). There is evidence of crude simulation of body language in today's text-based CMC environments: for example, emotional icons are used extensively in chat rooms and newsgroup messages to give users the ability to express emotion. Real-life communication however makes far more extensive use of non-verbal mechanisms.

Facial expressions are very important mechanisms for expressing emotion, agreement (or disagreement) and understanding (or confusion). Glancing and eye contact are also important aspects of body language. As with body orientation, the direction of a person's gaze displays a spatial focus of attention: it is used for initiating, maintaining, and ending a conversation. It is also used extensively in group conversations, which require non-verbal turn-taking cues. The social subtleties of gaze and eye contact require a strong degree of presence within an environment for them to work effectively.

Recent research into visual embodiment within online environments has attempted to realize the possibilities of expressing a wide range of visually expressive social cues. While we will always play a balance between the technological capabilities of modern PCs and the high demands of virtual environments, modern PC hardware is now capable of rendering quite human-like avatars (online representations of "self"). Having human-like representations gives the potential for body language to be included as a communication channel. While the graphics of recent virtual environments have generally been rather unsophisticated, studies have shown that even crude block-like forms of avatars can be useful in communicating non-verbal social cues (Tromp \& Snowdon 1997). Despite the graphic simplicity, a user's awareness of the spatial proximity and orientation of others has a strong impact on the dynamics of group communication. The simple act of orientating an, albeit primitive, avatar towards another avatar can indicate a focused attention on what that avatar is verbally communicating. Such behaviour can be also effective in synchronizing communication channels in group-turn-taking. Furthermore, providing some information as to the work-related activity of other users has been shown as a very useful mechanism for coordinating our communications.

\section{Collaborative Virtual Environments}

Collaborative Virtual Environments (CVEs) are computer-enabled, distributed virtual spaces or places in which people can meet and interact with others, with agents and with virtual objects. CVEs vary greatly in their representational richness from $3 \mathrm{D}$ virtual reality to $2 \mathrm{D}$ and even text based environments. The main applications to date have been military and industrial team training, collaborative design and engineering, and multiplayer games.

CVEs can help meet some of the communication requirements that have long been recognized as important to interactive discussion, particularly when negotiation is a key role and complex topics are being discussed. Naively they may be seen as cheap alternatives to video conferencing and teleconferencing (indeed that is how they were generally seen during the early developments of CVEs). In reality however they can be far more effective for dispersed work: most significantly, they represent a shift in interacting with computers and communications technology in that they provide a space that contains or encompasses data representations and users (Snowdon et. al. 2001). Teleconferencing does not provide body language or other spatial cues - gaze direction, spatial presence and direct or peripheral awareness of the activity of participants. Videoconferencing does not create a feeling of co-location: you can't place people in relation to one another; other than knowing that someone is looking at the camera; you cannot tell what they are looking at (even if they are looking at the camera, who are they focusing on in the remote group of participants?) (Benford et al. 1995). Videoconferencing is also weak in terms of shared activity awareness (Fussell et al. 2000) and is not suitable for highly distributed deployment. Neither of these established conferencing technologies embed the work tools within the environment or provide a mechanism for innovative virtual tools to be realized. Modern CSCW increasingly see these as crucial factors when actual 
work practices (as opposed to just meetings) are to be carried out at a distance with the support of communications technology.

During the early days of CVEs (in the early 1990s), researchers put most emphasis on simulating face-toface co-presence as realistically as possible. More recently, it has been realised that this is not enough for genuinely useful CSCW, and indeed not necessarily even required. The CVE research community is actively pursuing a number of research directions, which are briefly outlined below. Each of these will have a bearing on the effectiveness of CVEs for DE:

1. Work artifact collaboration. In "real world" domains, collaborative work involves the interleaving of singular and group activities: this requires considerable explicit and implicit communication between collaborators. Individuals need to negotiate shared understandings of task goals, of task decomposition and sub-task allocation, and of task progress. It is important that collaborators know what is currently being done and what has been done in context of the task goals. Shared work artifacts are increasingly being embedded within CVEs. By making the actual work take place within the CVE, collaborators can be aware of each other's activities. The work artifacts become not only the subject of communication, but also the medium of communication: as one user manipulates and object, changes are visible to other users (Benford et. al. 1997; Snowdon et. al. 2001).

2. "What You See Is What I See" (WYSIWIS). Conversational and action analysis studies of traditional collaborative work have shown the importance of being able to understand the viewpoints, focuses of attention and of action of collaborators. However, the majority of CVEs do not have the graphical clarity or realism to support this in a literal way. Current research is developing mechanisms for supporting the WYSIWIS principle through alternative mechanisms (Büscher et. al. 2001; Hindmarsh et. al. 2001).

3. Chance meetings. Informal and unplanned meetings with colleagues are rarely provided for in collaborative tools, yet they are known to be crucial to the work of many workers, particularly knowledge-workers. Recent research has investigated mechanisms for supporting chance meetings without the requirement for explicit action by the user (McGrath \& Prinz 2001).

4. Peripheral awareness is increasingly seen as an important concept in collaborative work, as evidenced in ethnographic studies (e.g. Heath \& Luff 1996). It is clear that team members involved in parallel but independent ongoing activities need to be able to co-ordinate and inform their activities through background or peripheral awareness of one another's activities.

5. Non-verbal communications are known to have a strong effect on how utterances are interpreted. Research into alternative input mechanisms for capturing this type of information from the user has been underway for some time: recently, attempts are being made to make these mechanisms intuitive and non-intrusive (using, for example, real-time digital image processing and pattern recognition rather than expensive and often unwieldy motion-capture systems).

6. The "designing for two worlds" principle: as people work in virtual environments, they are never fully immersed in it but are always partially in the real world too. Few CVE designers to date have considered the boundary between the real and the virtual (Büscher et. al. 2001). Yet certain activities when carried out in the real world have a very strong impact that should be recognised in the virtual world - for example, leaving the office.

CVEs clearly have the potential to enable innovative and effective distance teaching techniques, involving for example debate, simulation, role play, discussion groups, brainstorming, and project-based group work. The emphasis can be placed on the human-to-human interactions as common understandings are negotiated and developed across differences of knowledge, skills and attitudes. The increased sense of social presence (in relation to that created by traditional DE tools) means that student absence or non- 
participation is less likely to go unnoticed. As CVEs become more sophisticated CSCW tools, they will surely become increasingly appropriate as platforms for DE. A number of experimental CVEs supporting collaborative/constructivist education in children are described in (Kirner et al. 2001). These have all been developed to teach very specific concepts and have provided highly specific virtual props for these purposes. Since these applications to date have been for children, little effort has been put into supporting content-heavy instruction, abstract topics, or communication and community for group-based discussion. Other efforts have been made to foster learning communities for educational purposes: Bruckman, for example, has used a text-based MUD to teach programming (Bruckman 1998). However, we are not aware of any modern CVE application for college-level DE: certainly, none that have been informed by the latest developments in CSCW.

In the next section of the paper we expand on the notion of CVEs as highly appropriate platforms for community-driven DE, and investigate some approaches for fostering online learning communities.

\section{Fostering a Distance Learning Community}

Becker \& Mark (1999), in reviewing the sociological and philosophical literature regarding social communities, identify the following preconditions that must be fulfilled before we may speak of a true community: identity persistence of the members; commonly shared normative fundament; existence and stability of social conventions; a common interest; a collective rationality; being rooted in the same geographical/local place; and, continuity of the group. Preece (2000) takes a somewhat more relaxed view of what constitutes an online community: people, who interact socially as they strive to satisfy their own needs or perform special roles; a shared purpose that provides a reason for the community; and, policies (assumptions, rituals, protocols, laws) that guide interaction. We will draw on these concepts in order to develop a list of requirements that we believe must be tackled if we are to have any hope of fostering an online distance learning community.

CVEs can provide richness of expression and personality, as well as "identity persistence" via appropriately detailed and customizable avatars. By fostering users' interest in one another's characters we will support the development of sociability and community (Raybourn, 2001).

One of the preconditions for community identified by Becker \& Mark, which is typically disregarded in discussions of online community, is: being rooted in the same geographical/local place. This is one of the key areas in which CVEs can be far more effective than other Internet technologies, by providing a strong sense of "place" (not literally rooted in physical geography, of course). There has been significant research in the CVE literature about the nature of space and place in physical and digital settings (Harrison \& Dourish, 1996). A "place" has inherent within it a notion of the activities that occur (take place) there a space only becomes a place when an understood activity is scheduled or ongoing. The migration from space to place contains within it not only the definition of a shared purpose, but also the evolution of social policies and appropriate virtual objects to support that shared purpose (Snowdon et. al. 2001). In his discussion about the crucial role of social narrative (norms, customs and shared myths) in the creation and sustaining of communities, Stubblefield (2000) makes a case for providing rich, persistent environments for assisting online communities (see also Evard et. al. 2001).

A useful mechanism for creating and sustaining an online community is to allow participants to be involved in its development (Palloff \& Pratt 1999; Huxor 2001; Raybourn 2001). Typically this might involve the posting of "home pages" providing personal information for colleagues to see. However, some recent publications in the CVE arena suggest that involvement in the development of the core environment itself may be far more powerful. Raybourn (2001) conducted an interesting online social experiment in a Multi User Domain (MUD) in which social roles, power and powerlessness were investigated as means to develop community. Her experiment involved negotiated collaborative development of the environment, and her results underlined the well-known fact that for an online environment to be successful, 
there have to be good reasons for people to use it. For work-driven CSCW, this is known to include the provision of useful collaborative tools within the environment. However for community-driven CSCW, this should also include mechanisms for fostering social activity - something which has rarely been recognised in CVE research. By focusing solely on work effectiveness, we risk missing out on social richness - this has indeed been a problem with technologies such as video conferencing, which typically provide spaces for interaction but not social places as meaningful platforms for communication: social behaviour is engendered by other important aspects of an environment beyond the mere provision of a shared co-ordinate system (Harrison \& Dourish, 1996). We would argue for the provision of purely social environmental artifacts to increase the sense of place and to help engender persistent and evolving meaning into the workspaces provided.

The potential for CVE-based communication to assist the forming of social conventions was evident from a series of experiments carried out by Becker \& Mark (1999). They investigated communication in a number of online CVEs with different communications capabilities, thus providing a number of interesting observations about the roles of communication tools. It was noted that commitment to a speaking partner was felt as a strong obligation when the CVE being used forced two avatars to be in spatial proximity before they could communicate with each other. Without this requirement of proximity, conversations tended to take on the shortened and chaotic nature commonly seen in text chat environments, and also users generally did not bother to move their avatars very often. The importance of graphical individuality was noted, as were the conventions for positioning avatars into separate groups when a discussion was ongoing. Conventions for privacy and personal space were also in evidence.

One of the most important stages in community development (traditional or online) involves the negotiation of rules, conventions and common goals; this is often a stage of conflict but one that must be worked through if the community is to establish itself. Difficulties in achieving this in a text-only environment have been reported; indeed due to the absence of important conversational phenomena these conflicts can be worse than their face-to-face equivalents and can suffer from misinterpretations and misunderstandings. We would suggest that by humanizing the environment and enriching the communication media, these problems can be helped.

It is often stated that a virtual social space for students to congregate in is essential to distance courses (e.g. Harasim et al. 1996; Berge \& Collins 1995). However, the modern thinking in CSCW would suggest that it is better if an environment is designed in such a way that collaborators meet informally as a matter of course as they go about their work, rather than having to explicitly log on to a social environment. This can be achieved by designing virtual environments that offer the means to access appropriate information and task-related tools as well as communication tools. If these things are not provided, then the CVE is merely a graphically-rich communication tool - not unlike teleconferencing and videoconferencing which will lose out on the ability to act as a place, foster community, and enable important collaborative work principles such as work artifact collaboration, chance meetings, and peripheral awareness.

\section{Towards a CVE-based Support Tool for a Collaborative Learning Community}

The architecture of a CVE that would support the development of a learning community should be based on the pedagogical requirements of the community. Since the core activity of constructivist learning is collaborative interaction, localized sites that support this activity must be central to the overall system environment. Other peripheral locations should also be used to support the social and academic needs of this critical activity.

A central "place" should be used to support collaborative activity in groups. Within this place there should be a provision of college resources that group members can interact with to assist in the process of 
collaboration. Appropriate resources and would include document drop-off points, real-time application sharing facility points, whiteboarding tools, and structured and navigable course content with user annotations, attachments and web-links. Semantically-structured information visualization is an important area in itself, and one that is eminently suitable for collaborative investigation: see for example (Chen 1999). Resources could include both public shared objects and private objects with restricted access. Furthermore, embodiments within such sites should have extensive capabilities for non-verbal expression. Along with the visual cues of body language, the application of streaming audio could add non-verbal auditory cues of tone and volume of voice.

In order to promote cohesive supportive groups within these collaborative sites, group sizes should be kept to a minimum (Bernard et. al. 2000): these small groups can then act as "comfort zones" that promote social and academic confidence in members. It has commonly been noted that many students have a tendency to refrain from asking questions within large social forums (Stacey 1999): in situations of large class populations, classes can therefore be broken into several "collaborative cells". Each cell would be assigned to a separate spatial environment that is independent of other cells. Since each group would then (hopefully) develop a sense of "ownership" of these spaces, they should also be allowed to freely add to, or alter, such environments to develop a stronger "sense of place" within them. As confidence is developed within each of these cells, merging of cells could then take place. Social interaction would then expand as cell sizes grow; as a result, greater possibilities for collaborative learning would arise.

Students should not be confined to these private "collaborative zones". Students within these cells would need to interact with the student population as a whole. The provision of public social sites for the facilitation of informal interaction would be required to develop a sense of a "Campus Population". Furthermore, visiting such a site should not be the sole result of a proactive desire to socialize: students should have other needs to visit. This "campus" should therefore have academic resources that are in demand by the student population in general, which will have the effect of generating casual social encounters while students go about their academic business. Sites for academic resources should neighbour social chat sites within the same shared environment. Such sites should also have similar environmental resources as the collaborative zones. This will support "on-the-fly" student collaboration. (e,g spontaneous collaboration on homework assignments). An environment of this nature would also act as a social support mechanism for the collaborative learning process.

A third type of virtual space would be used for formal learning: lecture rooms. These "rooms" would not necessarily need a spatial component, but should have shared whiteboards/notes facilities and limited streaming video and /or audio. The literature investigating the effects of delay or "lag" on communication (caused by insufficient bandwidth or quality-of-service) shows that conversation tends to become very formalized as subtle cues for conversational phenomenon such as floor-taking, interactive gaze, facial expressions, and body language are removed (e.g. Bowers et al. 1996). The interesting fact is that a lecture is inherently a very formal environment, and therefore limited (one-person at a time) audio/video streaming and formal mechanisms for floor taking are, in our opinion, perfectly acceptable in this environment.

Our proposal is that the provision of these 3 distinct types of virtual space (collaborative zones, common student campus, and lecture rooms) within a CVE should greatly assist the development of a productive learning community in which students' social, academic, and collaborative needs are met.

\section{Conclusions}

We have discussed the needs for enhanced communication and community in DE, and have proposed that these needs may be met through the thoughtful application of CVEs. We have paid particular attention to the mechanisms by which rich communication and sociability may be supported, and have discussed these within the context of the latest thinking in CVEs and CSCW. 
Finally, we have outlined a proposed CVE-based solution for DE. Our belief is that the CVE can become the unifying element in which many of the tools of DE are deployed: it can provide the opportunity for planned and unplanned social encounters to take place, and provide tools for these encounters to enjoy enriched communication and improved synchronous work practices. Further, the 3D spatial metaphor itself is known to be a powerful mechanism for personal or collaborative knowledge exploration and information retention.

As a research discipline, CVEs are fairly recent, being recognizable as an area only since the early 1990 s. There are certainly important aspects of CVEs that still need further work: for example, the avatars in current CVEs tend to be limited in terms of their expressive capabilities, leading to crucial weaknesses such as a lack of assurance, understanding, and attention cues (Ståhl, 1999). However, we believe that continuing research into the nature of human-to-human communication, both conscious and unconscious, in conjunction with continuing CSCW research in the areas of work collaboration, intuitive and non-intrusive interfaces, will gradually solve these issues. We believe that useful environments for DE can now be built, and indeed that they should be, so that they can inform future developments of CVEs.

\section{References}

Baker, B., Harvell, T., \& Yuan, Z. (1996). A Collaborative Class Investigation into Telecommunications in Education: Teaching Via Telecommunications. Retrieved 1 November, 2001 from the World Wide Web: http://disted.tamu.edu/chapteri.htm

Becker, B., \& Mark, G. (1999). Constructing Social Systems through Computer-Mediated Communication. Virtual Reality,4, 60-73.

Benford, S., Bowers, J., Fahlén, L.E., Greenhalgh, C. \& Snowdon, D. (1995). User Embodiment in Collaborative Virtual Environments. Proceedings ACM CHI'95. Retrieved 1 November, 2001 from the World Wide Web: http://www.acm.org/sigchi/chi95/Electronic/documnts/papers/sdb_bdy.htm

Benford, S., Snowdon, D., Colebourne, A., O’Brien, J. \& Rodden, T. (1997). Informing the Design of Collaborative Virtual Environments. Proceedings ACM GROUP' '97, 71-80.

Berge, Z. \& Collins, M. (1995). Computer-Mediated Communication and the Online Classroom in Distance Learning. Computer-Mediated Communication Magazine, 2(4), 6-13.

Bernard, R.M., de Rubalcava, B.R., \& St-Pierre, D. (2000). Collaborative Online Distance Learning: Issues for Future Practice and Research. Distance Education, 21(2), 260-277.

Bowers, J., Pycock, J., \& O’Brien, J. (1996). Talk and Embodiment in Collaborative Virtual Environments. Proceedings ACM CHI'96. Retrieved 1 November, 2001 from the World Wide Web: http://www.acm.org/sigchi/chi96/proceedings/papers/Bowers/jb_txt.htm

Bruckman, A. (1998). Community Support for Constructionist Learning. The Journal of Collaborative Computing, 7, 47-86.

Büscher, M., O’Brien, J., Rodden, T., \& Trevor, J. (2001). "He's Behind You”: The Experience of Presence in Shared Virtual Environments. In Churchill, E.F., Snowdon, D.N. \& Munro, A.J. (eds) Collaborative Virtual Environments: Digital Places and Spaces for Interaction. London: Springer-Verlag, 77-98.

Cano, V., Hatar, C., \& Zapatero, A. (1999). Teleworking: Structural and Implementation Difficulties. Retrieved 1 November, 2001 from the World Wide Web: http://imdept.qmuc.ac.uk/imres/fulltxt/txt_VC2.htm

Chambers, M. (1999). The Efficacy and Ethics of Using Digital Multimedia for Educational Purposes. In Tait, A. \& Mills, R. (eds): The Convergence of Distance and Conventional Education: Patterns of Flexibility for the Individual Learner. London: Routledge, 5-16.

Chen, C. (1999). Information Visualisation and Virtual Environments. London: Springer.

Eklund, J. \& Eklund, P. (1997). Collaboration and Networked Technology: A Case Study in Teaching Educational Computing. Journal of Educational Computing in Teacher Education, 13. 14-19.

Evard, R., Churchill, E.F. \& Bly, S. (2001). Waterfall Glen: Social Virtual Reality at Work. In Churchill, E.F., Snowdon, D.N. \& Munro, A.J. (eds) Collaborative Virtual Environments: Digital Places and Spaces for Interaction. London: SpringerVerlag, 265-281. 
Collaborative Virtual Environments

Fussell, S.R., Kraut, R.E. \& Siegel, J. (2000). Coordination of Communication: Effects of Shared Visual Context on Collaborative Work. Proceedings ACM CSCW'00, 21-30.

Harasim, L., Hiltz, S.R., Teles, L., \& Turoff, M. (1996). Learning Networks. Cambridge, Mass: MIT Press.

Harrison, S. \& Dourish, P. (1996). Re-Placing Space: the Roles of Place and Space in Collaborative Systems. Proceedings ACM CSCW' $96,67-76$.

Hiltz, S.R. (1998). Collaborative Learning in Asynchronous Learning Networks: Building Learning Communities. Invited Address Web'98.

Hindmarsh, J., Fraser, M., Heath, C. \& Benford, S. (2001). Virtually Missing the Point: Configuring CVEs for Object-Focused Interaction. In Churchill, E.F., Snowdon, D.N. \& Munro, A.J. (eds) Collaborative Virtual Environments: Digital Places and Spaces for Interaction. London: Springer-Verlag, 115-139.

Huxor, A. (2001). The Role of the Personal in Social Workspaces: Reflections on Working in AlphaWorld. In Churchill, E.F., Snowdon, D.N. \& Munro, A.J. (eds) Collaborative Virtual Environments: Digital Places and Spaces for Interaction. London: Springer-Verlag,. 282-296.

Jonassen, D., Davidson, M., Collins, M., Campbell, J., \& Haag B. (1995). Constructivism and Computer-Mediated Communication in Distance Education. The American Journal of Distance Education, 9(2), 7-26.

Kirner, T.G., Kirner, C., Kawamoto, A.L.S., Cantao, J., Pinto, A., \& Wazlawick, R.S. (2001). Development of a Collaborative Virtual Environment for Educational Applications. Proceedings WEB3D 2001, 61-68.

McGrath, A. \& Prinz, W. (2001). All That is Solid Melts Into Software. In Churchill, E.F., Snowdon, D.N. \& Munro, A.J. (eds) Collaborative Virtual Environments: Digital Places and Spaces for Interaction. London: Springer-Verlag,. 99-114.

Nipper, S. Third Generation Distance Learning and Computer Conferencing. Retrieved 20 June, 2001 from the World Wide Web:. http://www-icdl.open.ac.uk/mindweave/chap5.html

Palloff, R.M. \& Pratt, K. 1999. Building Learning Communities in Cyberspace: Effective Strategies for the Online Classroom. San Francisco: Jossey Bass.

Preece, J. (2000). Online Communities: Designing Usability, Supporting Sociability. New York: Wiley.

Raybourn, E.M. (2001). Designing an Emergent Culture of Negotiation in Collaborative Virtual Communities: The DomeCityMOO Simulation. In Churchill, E.F., Snowdon, D.N. \& Munro, A.J. (eds) Collaborative Virtual Environments: Digital Places and Spaces for Interaction. London: Springer-Verlag,. 247-264.

Snowdon, D., Churchill, E.F. \& Munro, A.J. (2001). Collaborative Virtual Environments: Digital Spaces and Places for CSCW: An Introduction. In Churchill, E.F., Snowdon, D.N. \& Munro, A.J. (eds) Collaborative Virtual Environments: Digital Places and Spaces for Interaction. London: Springer-Verlag. 3-17.

Stacey, E. (1999) Collaborative Learning in an Online Environment. Journal of Distance Education, 14(2), Retrieved 22 November, 2001 from the World Wide Web: http://cade.athabascau.ca/vol14.2/stacey.html

Ståhl, O. (1999). Meetings for Real - Experiences from a Series of VR-Based Project Meetings. Proceedings Virtual Reality Systems \& Technology (VRST) 99, 164-165.

Strommen, E. F., \& Lincoln, B. (1992). Constructivism, technology, and the future of classroom learning. Education and Urban Society, 24(4), 466-477.

Stubblefield, W.A. (2000). Narrative Structure in Virtual Collaborative Environments. ACM SIGGROUP Bulletin, 21(1), 2223.

Tromp, J. \& Snowdon, D. (1997). Virtual Body language: providing Appropriate User Interfaces in Collaborative Virtual Environments. Proceedings ACM VRST '97, 37-44.

Whittaker, S., Frohlich, D., \& Daly-Jones, O. (1994). Informal Workplace Communication: What Is It Like and How Might We Support It? Proceedings ACM CHI '94, 131-137.

\section{Biographies}

Dr. Sam Redfern is a junior lecturer in the I.T. Dept. of the National University of Ireland, Galway. His postgraduate and postdoctoral research career encompasses some 9 years of applied technical research in areas such as simulation, real-time graphics and multimedia, digital image processing, and pattern recog- 
nition. His current research interests include the nature and support of online community, and collaborative virtual environments as platforms for computer supported co-operative work.

Mr. Niall Naughton, a native of Galway, Ireland, has being a postgraduate student at the department of Information Technology at NUI, Galway, for the past two years. He is currently working on his research Masters thesis, which will focus on the benefits of applying the visual media of computer virtual environments to improve online communication and collaboration, and an increased sense of "community". Niall has had a strong interest in the application of interactive media and computer graphics for several years, and hopes by the end of his thesis, he will have developed a prototype environment, which will specialize in the requirements of online distance education and virtual universities. Prior to his postgraduate studies, Niall graduated with a degree in Applied Physics from NUI, Galway. Since then he has worked in areas of material research and quality control in both Ireland and America. 